Published in final edited form as:

Chem Res Toxicol. 2019 June 17; 32(6): 1082-1086. doi:10.1021/acs.chemrestox.8b00398.

\title{
Hydrolyzable Tannins Are Iron Chelators That Inhibit DNA Repair Enzyme ALKBH2
}

\author{
Fangyi Chen ${ }^{\dagger} \ddagger$, Qi Tang ${ }^{\ddagger}$, Hang Ma ${ }^{\ddagger}$, Ke Bian, Navindra P. Seeram, Deyu Li ${ }^{*}$ \\ Department of Biomedical and Pharmaceutical Sciences, College of Pharmacy, University of \\ Rhode Island, Kingston, Rhode Island 02881, United States
}

\begin{abstract}
Hydrolyzable tannins are a class of polyphenolic compounds commonly found in natural products. In this work, we studied the in vitro inhibitory mechanism of six molecules in this class on ALKBH2, an $\mathrm{Fe}(\mathrm{II}) / \mathrm{a}$-ketogluta-rate-dependent DNA repair enzyme in the AlkB family. We determined the $\mathrm{IC}_{50}$ values of these compounds on the repair of 3-methylcytosine and 1methyladenine, the prototypical substrates of ALKBH2. A structure-activity relationship was also observed between the strength of inhibition and the number of galloyl moieties in a molecule. In addition, we found that the inhibition by this class of polyphenolic compounds on ALKBH2 is through an iron-chelating mechanism.
\end{abstract}

\section{Graphical Abstract}

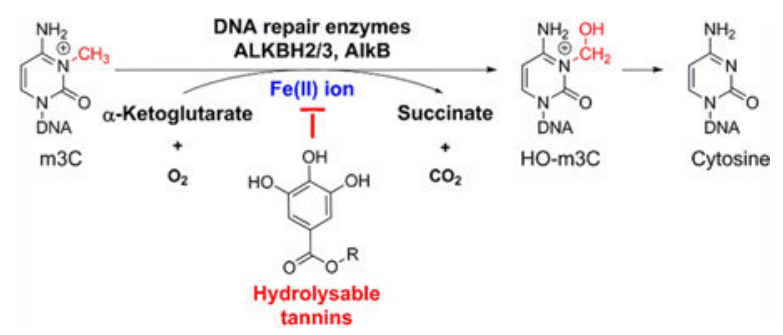

\section{INTRODUCTION}

Hydrolyzable tannins including ellagitannins and gallotannins are a class of polyphenolic compounds that are commonly found in a variety of fruits and plants, such as berries and oak barks. ${ }^{1,2}$ These molecules share a general structural motif of galloyl group(s) and have been shown to exhibit many health benefits including antioxidative, antiproliferative, and neuroprotective effects. ${ }^{3}$ Recent studies have revealed the involvement of hydrolyzable

\footnotetext{
*Corresponding Author Address: 7 Green House Rd., Pharmacy Building, Room 495 N, Kingston, RI 02881. Phone: (401) 874-9361. deyuli@uri.edu.

†resent Address Xiamen University, 4221 Xiang An South Road, Xiang An District, Xiamen, Fujian 361102, P.R. China. Author Contributions

\$ These authors contributed equally.

The authors declare no competing financial interest. ASSOCIATED CONTENT

Supporting Information

The Supporting Information is available free of charge on the ACS Publications website at DOI: 10.1021/acs.chemres-tox.8b00398.
} 
tannins, as iron chelators, in mitigating iron-overload induced hepatotoxicity and neurological disorders. ${ }^{4}$ Despite the positive effects, concerns have been raised on the safety of overconsumption of natural products containing hydrolyzable tannins, especially with the lack of evidence in the relationship between cellular uptake of these compounds and activity of many iron-related enzymes. There are about $80 \mathrm{Fe}(\mathrm{II}) / a$-ketoglutarate $(a \mathrm{KG})$-dependent enzymes in the human body, including TET, JmjC, and AlkB family proteins. ${ }^{5}$ In this paper, we focus on the DNA repair enzyme ALKBH2 in the AlkB family, which uses an Fe(II)/ $a$ KG-dependent mechanism to repair alkyl nucleic acid lesions induced by endogenous and environmental alkylating agents (Figure 1a). ${ }^{6,7}$

The AlkB family proteins include nine human homologues (ALKBH1-8 and FTO).

Among them, ALKBH2 has been identified as the major repair enzyme to lesions in both ssand ds-DNA, and ALKBH3 has activity mainly on lesions in ss- DNA., ${ }^{56}$ A number of alkyl substrates have been reported for the AlkB enzymes including 3-methylcytosine (m3C), 1methlyadenine (m1A), 1,N-ethenoadenine, 3, $\mathrm{N}^{4}$-ethenocytosine, and other alkyl adducts on the DNA bases. Among these adducts, $\mathrm{m} 3 \mathrm{C}$ and $\mathrm{m} 1 \mathrm{~A}$ have been demonstrated as the best substrates of AlkB. ${ }^{6,8}$ Considering the important role of the AlkB enzymes in maintaining genome integrity and the previous observations of hydrolyzable tannins as metal chelators, we questioned whether hydrolyzable tannins could affect the activity of the AlkB proteins by chelating the cofactor Fe(II) ion. In this study, we investigated the potential of six hydrolyzable tannins (structures 2 to 7, Figure 1b), as a new class of inhibitor to the AlkB enzymes. We extracted and purified a series of ellagitannins and gallotannins to evaluate their inhibitory effects on the repair efficiency of $\mathrm{m} 3 \mathrm{C}$ and $\mathrm{m} 1 \mathrm{~A}$ by the $\mathrm{ALKBH} 2$ protein by removing the $\mathrm{Fe}$ (II) ion cofactor in the enzymatic reaction. In addition, we observed a structure-activity relationship between the strength of inhibition and the number of galloyl groups in these hydrolyzable tannins. Our results offer a new perspective into the potential effect of overdosing hydrolyzable tannins that could lead to the inhibition of iron-dependent enzymes, which will be confirmed by in vivo studies with the consideration of bioavailability and metabolism.

\section{EXPERIMENTAL PROCEDURES}

Materials.

Rhein (1), gallic acid (2), ellagic acid (3), and tannic acid (7) were purchased from SigmaAldrich Chemical Co. (St. Louis, MO, USA). Ellagitannin (punicalagin 6) was isolated from a commercially available pomegranate extract (Pomella) provided by Verdure Sciences (Noblesville, IN, USA) using our previously reported methods. ${ }^{9}$ Gallotannins including ginnalin A (4) and pentagalloyl glucose (5) were isolated from a red maple leaf extract and sumac fruit extract, respectively, as we previously reported. ${ }^{10,11}$

\section{DNA Synthesis.}

Sixteen-mer oligonucleotides with a sequence of $5^{\prime}$-GAAGACCTXGGCGTCC-3', where X designates $\mathrm{m} 3 \mathrm{C}$ or $\mathrm{m} 1 \mathrm{~A}$, were synthesized by applying automated solid-phase phosphoramidite chemistry on a Mermade-4 DNA synthesizer. ${ }^{12}$ The concentration of oligonucleotides were measured by NanoDrop (Thermo Scientific) under UV absorbance of 
$260 \mathrm{~nm}$. The extinction coefficient $(\mathcal{E})$ of a lesion is calculated as its unmodified counterpart due to the tiny value difference in a $16 \mathrm{mer}$ context. All the oligonucleotides were purified by reverse-phase HPLC with a Phenomenex Luna Semi-Preparative $(10 \times 250 \mathrm{~mm}, 5 \mu \mathrm{m}) \mathrm{C} 18$ column. Solvent A was $100 \mathrm{mM}$ 1:1 triethylamine-acetic acid (TEAA), and B was 100\% acetonitrile. The oligonucleotides were characterized by LC-ESI-TOF-MS (AB Sciex) under negative ionization mode, the liquid chromatographic separation was conducted using a Phenomenex Luna C18 column $(4.6 \times 100 \mathrm{~mm} ; 5 \mu \mathrm{m})$ at a flow rate of $0.4 \mathrm{~mL} / \mathrm{min}$. Solvent A was $10 \mathrm{mM}$ ammonium acetate in water, and solvent B was $100 \%$ acetonitrile.

\section{Protein Purification.}

The ALKBH2 protein was expressed and purified as previously described. ${ }^{13}$ Briefly, the $A L K B H 2$ gene was cloned into the pET28a+ vector and then transformed into E. coli BL21 (DE3) pLysS cell for expression. The his-tagged proteins were purified by affinity column chromatography using Fast Protein Liquid Chromatography (GE healthcare). Thrombin was added to digest His-tagged proteins overnight followed by further purification using ionexchange chromatography. The purified ALKBH2 proteins were stored in an ALKBH buffer containing $300 \mathrm{mM} \mathrm{NaCl}, 10 \%$ glycerol, $50 \mathrm{mM} \mathrm{N}$-[tris(hydroxymethyl)methyl]-3aminopropanesulfonic acid, and $1 \mathrm{mM}$ 2-mercaptoethanol under $\mathrm{pH}$ 8.0.

\section{Enzymatic Assay and Inhibition Mechanism Study.}

For the enzyme inhibition studies, $5 \mu \mathrm{M}$ single-stranded m3C/m1A DNA oligonucleotides were incubated with $1.25 \mu \mathrm{M}$ ALKBH2 proteins in $46.5 \mathrm{mM}$ HEPES buffer (pH8.0) containing $50 \mu \mathrm{M} a \mathrm{KG}, 5 \mu \mathrm{M} \mathrm{Fe}\left(\mathrm{NH}_{4}\right)_{2}\left(\mathrm{SO}_{4}\right)_{2}$, and $1.86 \mathrm{mM}$ ascorbic acid in a $20 \mu \mathrm{L}$ reaction volume at $37{ }^{\circ} \mathrm{C}$ for $1 \mathrm{~h} .{ }^{13}$ To test the $\mathrm{IC}_{50}$ values, the concentrations of hydrolyzable tannins used were optimized individually to achieve inhibition percentages that can be accurately measured. For the inhibition mechanism studies, the concentration of $a \mathrm{KG}$ was fixed to $93 \mu \mathrm{M}$, and different concentrations of $\mathrm{Fe}\left(\mathrm{NH}_{4}\right)_{2}\left(\mathrm{SO}_{4}\right)_{2}(5,10,20,40,80$ $\mu \mathrm{M}$ ) were used for the $\mathrm{Fe}(\mathrm{II})$ chelator test. In contrast, varying concentrations of $a \mathrm{KG}$ (50, $100,200,400,800 \mu \mathrm{M})$ and fixed $10 \mu \mathrm{M} \mathrm{Fe}\left(\mathrm{NH}_{4}\right)_{2}\left(\mathrm{SO}_{4}\right)_{2}$ were used for the $a$-ketoglutarate competitor test. The enzyme activity was inactivated by adding $10 \mathrm{mM}$ ethylenediaminetetraacetic acid followed by heating up to $95^{\circ} \mathrm{C}$ for $5 \mathrm{~min}$. The analyses were performed by HPLC, and all data represent the mean \pm standard deviation (SD) of three independent experiments. The inhibition efficiency of a certain compound was obtained by comparing to the solvent control. The $0 \%$ inhibition was defined as no difference to the repair efficiency of the solvent control, and the $100 \%$ inhibition was defined as $0 \%$ repair of a certain substrate. The experimental data of a certain compound were fitted by the nonlinear polynomial fitting from Excel, and the $\mathrm{IC}_{50}$ value was calculated correspondingly.

\section{HPLC Analysis.}

$\mathrm{m} 3 \mathrm{C} / \mathrm{m} 1 \mathrm{~A}$ and its repaired product C/A were analyzed by using a DNApac PA-100 anionexchange column $(4 \times 250 \mathrm{~mm}, 13 \mu \mathrm{m})$ with solvent $\mathrm{A}$ as water and solvent B as $1.5 \mathrm{M}$ ammonium acetate in water. The flow rate was at $1.0 \mathrm{~mL} / \mathrm{min}$. A solvent gradient was carried out under the following conditions: $60 \%$ of B for $6 \mathrm{~min}, 60 \%-80 \%$ for $0.5 \mathrm{~min}, 80 \%$ for $1 \mathrm{~min}, 80 \%-60 \%$ for $0.5 \mathrm{~min}$, and $60 \%$ for $4 \mathrm{~min}$. 


\section{RESULTS AND DISCUSSION}

Our lab has extensively investigated the repair reactions of ALKBH2 and other AlkB family enzymes under various conditions, including reactions under ss- and ds-DNA conditions and with the presence of different inhibitors, such as copper ion and D-/L-2-hydroxy-glutarate. ${ }^{12-14}$ Although ALKBH2 prefers ds-DNA repair, we did not find a big difference between ss- and ds-DNA reaction conditions. Because there are many factors for an enzymatic reaction (such as $a \mathrm{KG}, \mathrm{Fe}(\mathrm{II})$ ion, protein and DNA), we chose to use ss- DNA for all inhibition reactions on ALKBH2 to simplify the analysis. To test the inhibitory effects of hydrolyzable tannins on ALKBH2, 16mer oligonucleotides bearing a site-specific m3C/m1 A adduct, the primary substrate of ALKBH2, were synthesized by using solid-phase phosphoramidite chemistry. ${ }^{12,15}$ The recombinant human ALKBH2 protein was expressed and purified according to previous studies. ${ }^{13,14}$ Then, the repair efficiency of ALKBH2 on $\mathrm{m} 3 \mathrm{C} / \mathrm{m} 1 \mathrm{~A}$ was assessed. For the enzymatic reactions, the $\mathrm{m} 3 \mathrm{C} / \mathrm{m} 1 \mathrm{~A}$-containing oligonucleotides were incubated with ALKBH2 in the presence of two cofactors ( $a \mathrm{KG}$ and $\mathrm{Fe}(\mathrm{II})$ ion) and other necessary reagents and buffers (see Experimental Procedures for details), and the repair ratio of $\mathrm{m} 3 \mathrm{C} / \mathrm{m} 1 \mathrm{~A}$ was quantified by HPLC after reaction. We used $5.0 \mu \mathrm{M}$ DNA and $1.25 \mu \mathrm{M}$ ALKBH2 for a typical enzymatic reaction to test the inhibition of different compounds; these concentrations are similar to the conditions previously reported. 14

The $\mathrm{IC}_{50}$ values of the six hydrolyzable tannins on inhibition of ALKBH2 repairing $\mathrm{m} 3 \mathrm{C}$ and $\mathrm{m} 1 \mathrm{~A}$ were determined. These compounds were either purchased or purified and characterized as reported. ${ }^{9-11}$ Rhein (compound 1, Figure 1b), a well-known inhibitor to the AlkB family enzymes was served as a positive control. ${ }^{16}$ The concentrations of rhein varied from 0 to $150 \mu \mathrm{M}$ and the $\mathrm{IC}_{50}$ values were found as $52.7 \mu \mathrm{M}$ for $\mathrm{m} 3 \mathrm{C}$ and $71.1 \mu \mathrm{M}$ for m1 A (Figure S1 and S8), which are comparable to the values on inhibiting AlkB and FTO reported by Li et al. ${ }^{16}$ For the hydrolyzable tannins, the concentrations were tested between 0 and $80 \mu \mathrm{M}$ (Figures S2-S7 and S9-S14). The $\mathrm{IC}_{50}$ values of compounds 2-7 were found from 1.8 to $38.2 \mu \mathrm{M}$ (Table 1 and Figures S2-S7 and S9-S14).

Interestingly, based on the structures of these hydrolyzable tannins, we found a correlation of their structural features to their $\mathrm{IC}_{50}$ values: as the number of galloyl groups in the molecule increases, the $\mathrm{IC}_{50}$ value decreases (Table 1). For example, the one galloyl unit containing compound 2 on $\mathrm{m} 3 \mathrm{C}$ has an $\mathrm{IC}_{50}$ of $38.2 \mu \mathrm{M}$, the five galloyl unit containing compound 5 has an $\mathrm{IC}_{50}$ of $18.9 \mu \mathrm{M}$, and the ten galloyl unit containing compound 7 has an $\mathrm{IC}_{50}$ of $3.9 \mu \mathrm{M}$. Both compounds 3 and 4 have two galloyl units, and they have similar $\mathrm{IC}_{50}$ values (25.5 and $22.6 \mu \mathrm{M}$, correspondingly). A similar trend was observed for m1 A repair. These results indicate that the basic galloyl unit of these derivatives are potentially the structural motif responsible for the inhibitory effects.

We further selectively explored the inhibition mechanism of representative compounds on the adduct repair by ALKBH2. Previously, rhein was reported as an inhibitor to AlkB and FTO by competitively replacing $a \mathrm{KG}$ in the active site. ${ }^{16,17}$ And hydrolyzable tannins, including tannic acid (compound 7), have been reported to ameliorate $\mathrm{Fe}(\mathrm{II})$ ion and reactive oxygen species-induced neurological diseases. ${ }^{18}$ In addition, tannic acid has been reported 
to mitigate iron overload by its chelating ability through the neighboring phenolic hydroxyl groups. ${ }^{4,19}$ We wanted to investigate the inhibitory mechanisms of the hydrolyzable tannins and chose tannic acid because of its reported activities and also because it has the most galloyl groups ${ }^{10}$ in the molecules tested here. In addition to compound 7 , we also selected compounds 2 ( 1 galloyl unit) and 5 (5 galloyl units) to study the inhibitory mechanism of hydrolyzable tannins.

We varied the concentration of $a \mathrm{KG}$ and the Fe(II) ion in the reactions without any inhibitor, and with rhein or hydrolyzable tannins. For the reactions without the inhibitor, small variations on the reactivity were found with $a \mathrm{KG}$ changing from 50 to $800 \mu \mathrm{M}(89 \%$ to $99 \%$, control in Figure 2a) and $\mathrm{Fe}(\mathrm{II})$ ion changing from 5 to $80 \mu \mathrm{M}$ (staying around $93 \%$, control in Figure 2b). First, we tested the reactivity change with different concentrations of $a \mathrm{KG}$ with a fixed $\mathrm{Fe}(\mathrm{II})$ ion concentration of $10 \mu \mathrm{M}$. When $50 \mu \mathrm{M}$ of rhein was added to the reaction medium, we found the repair ratio decreased to $30 \%$ with $50 \mu \mathrm{M} a \mathrm{KG}$. As the amount of $a \mathrm{KG}$ increased up to $800 \mu \mathrm{M}$, the repair efficiency was recovered in a concentration-dependent manner (Figure 2a). Then, we tested the reactivity change with different concentrations of $\mathrm{Fe}(\mathrm{II})$ ion (from 5 to $80 \mu \mathrm{M}$ ) with a fixed $a \mathrm{KG}$ concentration of $93 \mu \mathrm{M}$. The reactions with $50 \mu \mathrm{M}$ rhein all had a repair efficiency around $36 \%$ and showed no significant change even with the increment of $\mathrm{Fe}(\mathrm{II})$ ion to $80 \mu \mathrm{M}$ (Figure 2b). These observations are consistent with previously reported data of rhein and show that it is a competitive inhibitor to $a \mathrm{KG}$ but not an $\mathrm{Fe}(\mathrm{II})$ ion chelator. ${ }^{16,17}$ For compound 7 under variable concentrations of $a \mathrm{KG}$, all of the reactions with $2 \mu \mathrm{M}$ of it had a decreased repair efficiency down to $\sim 25 \%$ and did not vary significantly with the increment of $a \mathrm{KG}$ even to $800 \mu \mathrm{M}$ (Figure $2 \mathrm{a}, \mathrm{Fe}(\mathrm{II})$ ion kept at $10 \mu \mathrm{M}$ ). For the reactions with varying concentrations of $\mathrm{Fe}$ (II) ion, the reactivity was decreased to $5 \%$ with $5 \mu \mathrm{M} \mathrm{Fe}$ (II) ion and was restored in a concentration-dependent manner as Fe(II) ions stepwisely increased up to $80 \mu \mathrm{M}$ (Figure $2 \mathrm{~b}$, $a \mathrm{KG}$ kept at $93 \mu \mathrm{M})$. These data indicate that compound 7 is an Fe(II) ion chelator but not a competitive inhibitor to $a \mathrm{KG}$. In addition to compound 7, we also tested compounds 2 and 5 under similar conditions to expand the generality of the iron chelating mechanism of hydrolyzable tannins. The results showed the repair efficiencies were also recovered in a concentration-dependent manner as Fe(II) ion concentration elevated (Figures S15 and S16).

Rhein has been reported as an inhibitor to $a \mathrm{KG} / \mathrm{Fe}(\mathrm{II})$ - dependent enzymes, including AlkB and FTO, through different mechanisms, such as a competitor to either $a \mathrm{KG}$ or DNA substrate. ${ }^{16,17}$ The hydrolyzable tannins tested in this work are metal chelators and thus could inhibit ALKBH2 and other $a \mathrm{KG} / \mathrm{Fe}$ (II)-dependent proteins. Besides chelating the metal ions, there might be additional inhibitory mechanisms for the hydrolyzable tannins. For example, the repair efficiency of ALKBH2 treated with compound 7 reached up to $60 \%$ even with the increment of $\mathrm{Fe}$ (II) ion concentration up to $80 \mu \mathrm{M}$ and could not be recovered to the level of the control ( 95\% repair, Figure $2 \mathrm{~b}$ ). These results indicate the inhibition may also come from the binding of compound 7 to the ALKBH2 protein, possibly leading the protein to a fully or partially inactive conformation.

In this study, we investigated hydrolyzable tannins as a new class of natural product inhibitors for ALKBH2, the major human DNA repair enzyme in the AlkB family. Hydrolyzable tannins have been identified as antioxidative, antiproliferative, and 
neuroprotective agents. Here, we discovered that these compounds are Fe(II) ion chelators that can decrease the level of free $\mathrm{Fe}(\mathrm{II})$ ion, which is critical for the catalytic activity of the AlkB family enzymes. If the chelation of the Fe(II) ion by the hydrolyzable tannins decreases the iron level too much, the reactivity of the AlkB enzymes might be inhibited. It is possible that the overconsumption of hydrolyzable tannins may affect iron homeostasis in the body, leading to the dysfunction of iron-dependent proteins, such as the AlkB homologues and other $\mathrm{Fe}(\mathrm{II}) / a \mathrm{KG}$-dependent enzymes. The results reported in this paper are from in vitro experiments. Further cellular or animal studies are needed to investigate the adverse effect demonstrated in this work.

\title{
Supplementary Material
}

Refer to Web version on PubMed Central for supplementary material.

\section{ACKNOWLEDGMENTS}

\author{
The authors want to thank the RI-INBRE program, its director Prof. Bongsup Cho, and staff Dr. Al Bach, Kim \\ Andrews, and Patricia Murray for their kind help. \\ Funding \\ This work was supported by an Institutional Development Award from the National Institute of General Medical \\ Sciences of the National Institutes of Health under grant number P20 GM103430. This work was also supported by \\ National Institutes of Health under grant numbers R15 CA213042 and R01 ES028865 (to D.L.).
}

\section{ABBREVIATIONS}

SS

ds

$a \mathrm{KG}$

m3C

m1A single stranded

double stranded

alpha-ketoglutarate

3-methylcytosine

1-methlyadenine

\section{REFERENCES}

(1). Okuda T, and Ito H (2011) Tannins of Constant Structure in Medicinal and Food PlantsHydrolyzable Tannins and Polyphenols Related to Tannins. Molecules 16, 2191-2217.

(2). Arapitsas P (2012) Hydrolyzable tannin analysis in food. Food Chem. 135, 1708-1717. [PubMed: 22953913]

(3). Chung KT, Wong TY, Wei CI, Huang YW, and Lin Y (1998) Tannins and human health: a review. Crit. Rev. Food Sci. Nutr. 38, 421-464. [PubMed: 9759559]

(4). Basu T, Panja S, Shendge AK, Das A, and Mandal N (2018) A natural antioxidant, tannic acid mitigates iron-overload induced hepatotoxicity in Swiss albino mice through ROS regulation. Environ. Toxicol. 33, 603-618. [PubMed: 29446234]

(5). Hausinger RP, and Schofield CJ (2015) 2-Oxoglutarate- dependent oxygenases, Royal Society of Chemistry, Cambridge, UK.

(6). Fedeles BI, Singh V, Delaney JC, Li D, and Essigmann JM (2015) The AlkB family of Fe(II)/aketoglutarate-dependent dioxygenases: repairing nucleic acid alkylation damage and beyond. J. Biol. Chem. 290, 20734-20742. 
(7). Yi C, and He C (2013) DNA repair by reversal of DNA damage. Cold Spring Harbor Perspect. Biol. 5, a012575.

(8). Sedgwick B (2004) Repairing DNA-methylation damage. Nat. Rev. Mol. Cell Biol. 5, 148-157. [PubMed: 15040447]

(9). Yuan T, Ma H, Liu W, Niesen DB, Shah N, Crews R, Rose KN, Vattem DA, and Seeram NP (2016) Pomegranate's neuroprotective effects against Alzheimer's disease are mediated by urolithins, its ellagitannin-gut microbial derived metabolites. ACS Chem. Neurosci. 7, 26-33. [PubMed: 26559394]

(10). Ma H, Liu W, Frost L, Kirschenbaum LJ, Dain JA, and Seeram NP (2016) Glucitol-core containing gallotannins inhibit the formation of advanced glycation end-products mediated by their antioxidant potential. Food Funct. 7, 2213-2222. [PubMed: 27101975]

(11). Ma H, Liu W, Frost L, Wang L, Kong L, Dain JA, and Seeram NP (2015) The hydrolyzable gallotannin, penta-O-galloyl- $\beta$-D-glucopyranoside, inhibits the formation of advanced glycation endproducts by protecting protein structure. Mol. BioSyst. 11, 1338-1347. [PubMed: 25789915]

(12). Chen F, Tang Q, Bian K, Humulock ZT, Yang X, Jost M, Drennan CL, Essigmann JM, and Li D (2016) Adaptive response enzyme AlkB preferentially repairs 1-methylguanine and 3methylthymine adducts in double-stranded DNA. Chem. Res. Toxicol. 29, 687-693. [PubMed: 26919079]

(13). Chen F, Bian K, Tang Q, Fedeles BI, Singh V, Humulock ZT, Essigmann JM, and Li D (2017) Oncometabolites D- and L-2-hydroxyglutarate inhibit the AlkB family DNA repair enzymes under physiological conditions. Chem. Res. Toxicol. 30, 1102-1110. [PubMed: 28269980]

(14). Bian K, Chen F, Humulock ZT, Tang Q, and Li D (2017) Copper inhibits the AlkB family DNA repair enzymes under Wilson's disease condition. Chem. Res. Toxicol. 30, 1794-1796. [PubMed: 28926697]

(15). Tang Q, Cai A, Bian K, Chen F, Delaney JC, Adusumalli S, Bach AC, Akhlaghi F, Cho BP, and Li D (2017) Characterization of byproducts from chemical syntheses of oligonucleotides containing 1-methyladenine and 3-methylcytosine. ACS Omega 2, 8205-8212. [PubMed: 29214236]

(16). Li Q, Huang Y, Liu X, Gan J, Chen H, and Yang C-G (2016) Rhein inhibits AlkB repair enzymes and sensitizes cells to methylated DNA damage. J. Biol. Chem. 291, 11083-11093. [PubMed: 27015802]

(17). Chen B, Ye F, Yu L, Jia G, Huang X, Zhang X, Peng S, Chen K, Wang M, Gong S, et al. (2012) Development of cell- active N6-methyladenosine RNA demethylase FTO inhibitor. J. Am. Chem. Soc. 134, 17963-17971.

(18). Chan S, Kantham S, Rao VM, Palanivelu MK, Pham HL, Shaw PN, McGeary RP, and Ross BP (2016) Metal chelation, radical scavenging and inhibition of $A \beta_{42}$ fibrillation by food constituents in relation to Alzheimer's disease. Food Chem. 199, 185-194. [PubMed: 26775960]

(19). Phiwchai I, Yuensook W, Sawaengsiriphon N, Krungchanuchat S, and Pilapong C (2018) Tannic acid (TA): A molecular tool for chelating and imaging labile iron. Eur. J. Pharm. Sci. 114, 64-73. 
a)<smiles></smiles>

3-methylcytosine (m3C)

b)<smiles>O=C(O)C1=CC(O)C2C(=O)c3cccc(O)c3C(=O)C2C1O</smiles>

1 Rhein<smiles>O=C(O)c1cc(O)c(O)c(O)c1</smiles>

2 Gallic acid<smiles>O=C(OCC(OC(=O)c1cc(O)c(O)c(O)c1)C(COC(=O)c1cc(O)c(O)c(O)c1)(OC(=O)c1cc(O)c(O)c(O)c1)OC(=O)c1cc(O)c(O)c(O)c1)c1cc(O)c(O)c(O)c1</smiles>

5 Pentagalloyl glucose
DNA repair enzymes

ALKBH2/3, AlkB

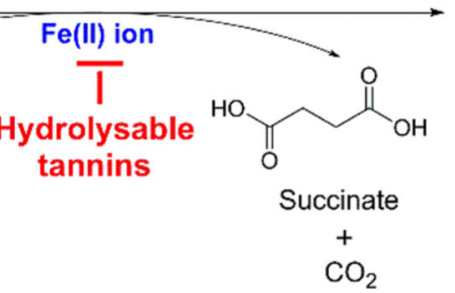<smiles>CCn1ccc(N)nc1=O</smiles>

HO-m3C

Cytosine<smiles></smiles>

3 Ellagic acid

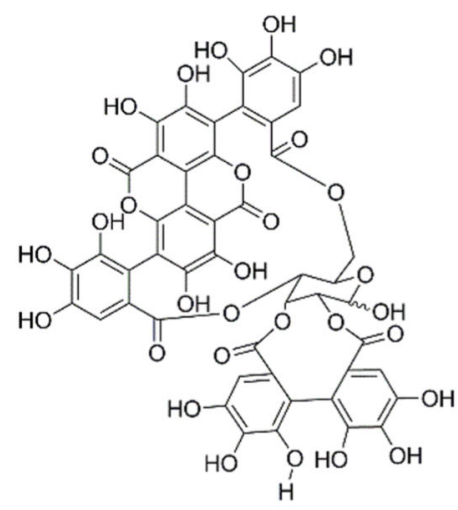

6 Punicalagin

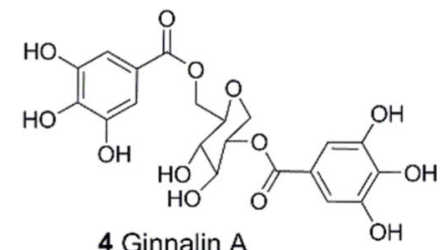<smiles>C=C(OC(=O)c1cc(O)c(O)c(O)c1)C(=O)O</smiles>

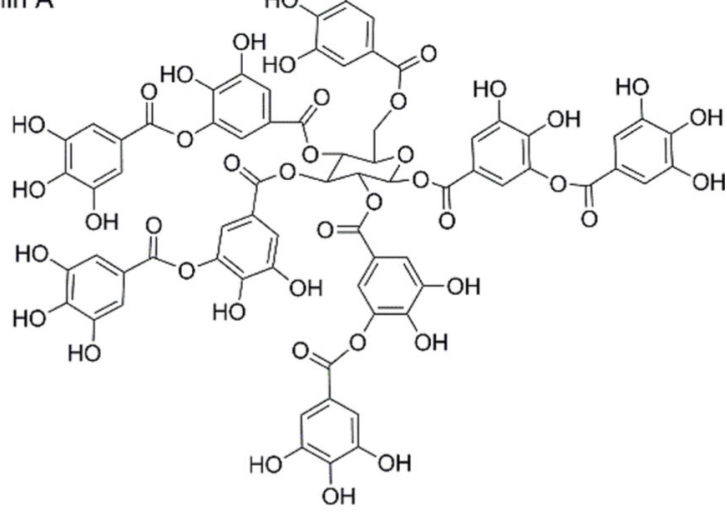

7 Tannic acid

Figure 1.

Repair mechanism of the AlkB family enzymes and structures of the hydrolyzable tannins and rhein.

Chem Res Toxicol. Author manuscript; available in PMC 2019 December 03. 

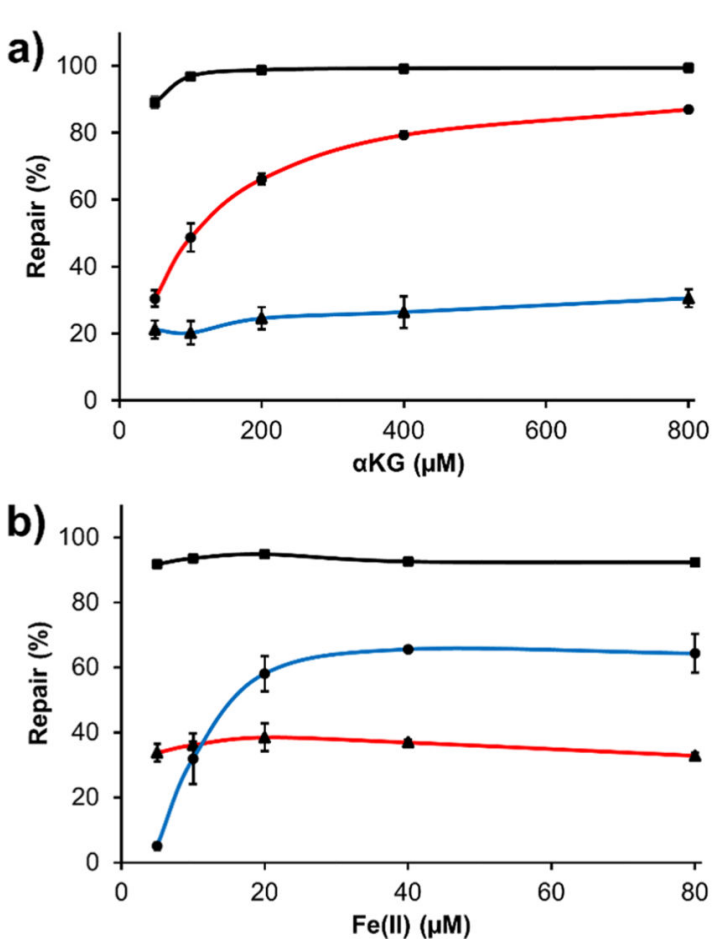

Figure 2.

Inhibition of $\mathrm{ALKBH} 2$ repair reactions by tannic acid and rhein (control: no inhibitor added). All of the tests were carried out in triplicate, and the error bars represent standard deviation. (a) Tests of compounds on the competition to $a \mathrm{KG}$ and (b) tests of compounds on the chelation to the Fe(II) ion.

Chem Res Toxicol. Author manuscript; available in PMC 2019 December 03. 
Table 1.

$\mathrm{IC}_{50}$ Values of Hydrolyzable Tannins Inhibiting the ALKBH2 Enzyme Repairing m3C and m1A

\begin{tabular}{cccc}
\hline compound & $\mathbf{I C}_{\mathbf{5 0}}(\boldsymbol{\mu} \mathbf{M})$ of $\mathbf{m 3 C}$ & $\mathbf{I C}_{\mathbf{5 0}}(\boldsymbol{\mu} \mathbf{M})$ of $\mathbf{~ m 1 A}$ & galloyl units \\
$\mathbf{2}$ & 38.2 & 30.9 & 1 \\
$\mathbf{3}$ & 25.5 & 28.3 & 2 \\
$\mathbf{4}$ & 22.6 & 10.6 & 2 \\
$\mathbf{5}$ & 18.9 & 6.9 & 5 \\
$\mathbf{6}$ & 8.1 & 2.5 & 6 \\
$\mathbf{7}$ & 3.9 & 1.8 & 10 \\
\hline
\end{tabular}

compound $\mathrm{IC}_{50}(\mu \mathrm{M})$ of $\mathrm{m} 3 \mathrm{C} \quad \mathrm{IC}_{50}(\mu \mathrm{M})$ of $\mathrm{m} 1 \mathrm{~A} \quad$ galloyl units 